Zorrilla, M., Modeste, N., Gleason, P., Sealy, D., Banta, J., Trieu, S./ Californian Journal of Health Promotion 2019, Volume 17, Issue 1, Pages 71-83.

\title{
Assessing Depression-Related Mental Health Literacy among Young Adults
}

\author{
Marcia M. Zorrilla ${ }^{1}$, Naomi Modeste ${ }^{1}$, Peter C. Gleason ${ }^{1}$, Diadrey-Anne Sealy ${ }^{2}$, Jim E. Banta ${ }^{1}$, \\ and Sang Leng Trieu ${ }^{3}$ \\ ${ }^{1}$ Loma Linda University, School of Public Health \\ ${ }^{2}$ University of the Southern Caribbean, School of Science and Technology \\ ${ }^{3}$ Mental Health Project Director/Program Evaluator Ohlone College, Student Health Center,
}

\begin{abstract}
Background and Purpose: Young adults who are 18 to 25 years old have the highest prevalence of depression (10.9\%). Depression is a risk factor for suicide. Mental health literacy (MHL) is a key component in assessing recognition and help-seeking for depression with suicidal ideation. This study investigated MHL as it relates to help-seeking for depression with suicidal ideation. Methods: A crosssectional survey design was used. Participants were young adults ( $n=430$, ages 18 to 24 years old) who lived, worked, and/or attended school in San Francisco, California. Reavley and colleagues' MHL survey was modified and made available in English, Spanish, and Chinese. Results: Several background factors were positively, though weakly, correlated to MHL, based on the r coefficient. Significant factors were: being female [r=.12, $\mathrm{p}<.05]$, white [r=.12, $\mathrm{p}<.05]$, San Francisco residency [r=.09, $\mathrm{p}<.1]$, and being in a relationship [ $\mathrm{r}=.08, \mathrm{p}<.1]$. The percentage [95\% confidence interval (CI)] of those who correctly labeled “depression with suicidal thought” for the vignette was 87.4\% (CI: 84.3, 90.6). Conclusions: Improving MHL among young adults, especially among males and racial and ethnic populations is needed. Additionally, educating young adults about alcohol use as an unhealthy option for depression is important.
\end{abstract}

(C) 2019 Californian Journal of Health Promotion. All rights reserved.

Keywords: depression, help-seeking, mental health literacy, young adults, San Francisco

\section{Introduction}

In the United States (U.S.), approximately one in five adults -44.7 million, or $18.3 \%$ experienced a mental illness within the past year (Substance Abuse and Mental Health Services Administration (SAMHSA), 2017). Depression, specifically, is a common diagnosis among young adults, ages 18 to 25; this age group experiences the highest prevalence of depression (10.9\%) when compared to adults ages 26 to $49(7.4 \%)$, and ages 50 and over (4.8\%) (SAMHSA, 2017a).

Depression typically presents itself during the developmental stage of adolescence. In transitional-aged youth (TAY), which is a developmental lifespan from older adolescence (e.g., 15 years old) to young adulthood up to age 26 (Wilens \& Rosenbaum, 2013), depression may continue from adolescence to adulthood (Patton et al., 2014) with multiple psychosocial and neurobiological changes, such as family history of depression, psychosocial stress, and hormonal factors (Thapar, Collishaw, Pine, \& Thapar, 2012). Depression has been identified as a major risk factor for suicide and other health problems such as obesity, tobacco use, and substance misuse (Thapar et al., 2012). Suicide is defined as death caused by self-directed injurious behavior with an intent to die as a result of the behavior(Centers for Disease Control and Prevention (CDC), 2011). In 2016, suicide was the second leading cause of death among 15 to 24-year-old youth (CDC, 2018).

\section{Mental Health Literacy (MHL)}

Before defining mental health literacy (MHL), a brief definition of its predecessor, health literacy, is in order. Health literacy refers to how well 
Zorrilla, M., Modeste, N., Gleason, P., Sealy, D., Banta, J., Trieu, S./ Californian Journal of Health Promotion 2019, Volume 17, Issue 1, Pages 71-83.

individuals can understand basic health information in order to make informed choices about their health care (CDC, 2015). Having low literacy may have a negative effect on health and health care given the complexity of health care systems in the U.S. (Berkman, Davis, \& McCormack, 2010; Manganello, Sentell, \& Davis, 2013). Jorm et al. (1997, p. 182) initially defined MHL as the "knowledge and beliefs about mental disorders which aid their recognition, management or prevention.” A more current definition of MHL also includes: understanding how to prevent mental disorders, recognizing symptoms of a developing mental disorder, knowing about help-seeking interventions and self-help strategies, and mental health first aid skills to help others experiencing a mental health crisis (Jorm, 2015).

The earliest MHL study, conducted by Jorm et al. (1997) in Australia, was a cross-sectional survey $(n=2,031$, ages 18 to 74$)$ using structured interviews and vignettes of a person with either depression or schizophrenia. Participants were asked what they thought was wrong with the person in the vignette; what type of help would be helpful or less helpful; and which on the list of treatments would be helpful or harmful. Of 2,031 participants, 1,010 were questioned on the depression vignette and 1,021 on the schizophrenia vignette. The researchers' findings showed that most of the participants did recognize some type of disorder in the vignettes, but with a low percentage of labelling the mental illness correctly (e.g., $72 \%$ for the depression vignette, with 39\% correctly labelling the mental illness as depression). Health care providers who were perceived as helpful in treating depression included general practitioners (83\%) and counselors (74\%), while psychiatrists (51\%) and psychologists (49\%) were less helpful. Poor MHL was noted for treatment options; vitamins and special diets were viewed as more helpful than medications.

Reavley et al. (2012) conducted a MHL study among college students and college staff (as a comparison group). Their study used telephone interviews and a depression vignette; 774 students and 422 staff members participated. Participants were asked what they thought was wrong with the person in the vignette; what type of help would be helpful or less helpful; and which list of treatments would be helpful or harmful. While over $70 \%$ of students and staff could correctly identify the mental disorder, intention to seek help among students and staff if they had a similar problem to the person in the vignette varied somewhat. For students, 26\% reported their intention to seek help from a general practitioner, $25 \%$ from friends, $14 \%$ from their parents, $12 \%$ from their family, $10 \%$ from a school counselor, and 3\% from a psychiatrist. For staff, 50\% reported their intention to seek help from a general practitioner, $15 \%$ from an employee assistance program, $13 \%$ from friends, $12 \%$ from a counselor, and $4 \%$ from a psychiatrist.

Soon thereafter, Reavley et al. (2014) conducted a study to assess MHL scales for the recognition of depression, depression with suicidal ideation, early schizophrenia, chronic schizophrenia, social phobia, and post-traumatic stress disorder using vignettes. In a telephone survey of 1,536 health professionals and 1,609 members of the general population, participants were randomly assigned to one of six vignettes and asked what they thought was wrong with the person in the vignette; what type of help would be helpful or not; and which treatment options would be helpful or harmful. The results from the health professionals and general population were compared. The variable "having a family member or a close friend with a problem like that described in the vignette" predicted significantly higher scores on all mental health scales (p. 68).

Many adolescents and young adults are unaware of the signs and symptoms of depression, which delays or avoids help-seeking for mental health treatment (Coles et al., 2016; Lam, 2014; Reavley, McCann, \& Jorm, 2012). Recognition of a mental disorder is generally the first step in the help-seeking process (Kelly, Jorm, \& Wright, 2007; Reavley \& Jorm, 2011; Reavley, Morgan, \& Jorm, 2014; Rickwood, Deane, Wilson, \& Ciarrochi, 2005). Early recognition of mental illness, especially depression and suicidal ideation, in young adults may lead to appropriate help-seeking for themselves (Kelly et al., 2007). Low levels of knowledge and recognition of 
Zorrilla, M., Modeste, N., Gleason, P., Sealy, D., Banta, J., Trieu, S./ Californian Journal of Health Promotion 2019, Volume 17, Issue 1, Pages 71-83.

depression affects help-seeking in that individuals tend to deal with depression on their own rather than obtaining professional help (Coles \& Coleman, 2010).

Most of the early research on MHL has been conducted in Australia. National MHL surveys have focused on the recognition of mental illness through vignettes and beliefs about appropriate treatments (Jorm et al., 1997; Reavley et al., 2012; Reavley et al., 2014). Current depressionrelated MHL research among adolescents and college-aged youth has been done elsewhere. In a study among college students $(n=350)$ in Vietnam, researchers found $32 \%$ of respondents correctly labeling depression in a vignette (Thai \& Nguyen, 2018). In the U.S., a New York study of adolescents $(n=1,104)$ by Coles et al. (2016) found $40 \%$ of the respondents correctly labeled the depression vignette. Miller, Cuthbertson, Skidmore, and Loveridge (2017) found 69\% of adults $(n=2,622)$ correctly identify depression in a national MHL study conducted in the U.S. However, MHL research remains limited in the U.S. for both adolescents and adults (Cheng, Wang, McDermott, Kridel, \& Rislin, 2018; Manganello et al., 2013). MHL research, especially depression with suicide ideation, has not been studied sufficiently.

MHL is a variable found to be important in assessing recognition and help-seeking for depression, depression with suicide ideation, anxiety, and other mental illnesses (Chamberlain, Goldney, Taylor, \& Eckert, 2012; Goldney, Fisher, Wilson, \& Cheok, 2002; Jorm, 2000; Reavley et al., 2014). The MHL scales developed by Reavley, Morgan, and Jorm (2014) was modified and used in the current study, along with a vignette on depression with suicidal ideation. Based on previous research (Reavley et al., 2014), several predictor variables (background factors) were included in linear regression analysis. They were: (a) age; (b) gender; (c) race and ethnicity; (d) educational level; (e) San Francisco residency; (f) relationship status; (g) depression status; (h) knowing a family member or friend with depression; (i) alcohol use; (j) marijuana use; (k) lifetime mental health services utilization; and (l) previous mental health services.

\section{The Current Study}

The aim of this study was to investigate MHL as it relates to help-seeking for depression with suicidal ideation among 18-24-year-old young adults from the San Francisco Bay Area. This study was a modified replication of MHL research done by Reavley et al. (2014). The research questions of interest were to: (a) examine the correlation of MHL and background factors (as described earlier), (b) to identify background factors that predict MHL, and (c) to assess MHL relating to recognition of and beliefs about treatment for depression with suicidal ideation.

\section{Study Design}

\section{Methods}

A cross-sectional online survey was made available August 2016 through March 2017. The online survey was pilot tested before being launched. The study's consent was available online and anonymous. The survey commenced with the consent and a "yes" or "no" option for participants to select; participation was voluntary. The Loma Linda University Institutional Review Board (IRB) approved the study.

\section{Sample and Procedure}

The original IRB proposal was for 600 participants forming two groups: non-students and students. However, there were recruitment challenges with non-students. Based on the 430 completed surveys, the G*Power 3 program (Faul, Erdfelder, Lang, \& Buchner, 2007) was used to calculated power. For the Pearson product-moment correlation coefficient test (medium effect size $=0.3, \alpha=0.05$ ), calculated post hoc power was 0.99 . For the linear regression test, with 16 predictors, (medium effect size $=0.15, \alpha=0.05$ ), power was 0.99 . For percent frequencies and 95\% intervals estimation (using t-test statistic, medium effect size 0.50 , $\alpha=0.05$ ), power was 0.96 .

The participants who made up the sample $(n=430)$ were 18 to -24-year-old young adults who lived, worked, and/or attended school in San Francisco. Participants represented any gender; race/ethnicity; sexual orientation; relationship status; and educational level up to Bachelor's 
degree if they could read and understand English, Spanish, or Chinese. The exclusion criteria for the study were minors; pregnant women; military personnel; and institutionalized young adults.

A study website was created and social media tools such as Instagram, Facebook, and Twitter used for recruitment. The study website was available in English, Spanish, and Chinese, and contained the link to a description of the study and to the online questionnaire. The study website URL was distributed to transitional aged youth (TAY) serving agencies, listservs, and facilities that provide health services for youth, ages 18 to 24, throughout the city and county of San Francisco such as college health centers and other youth-friendly clinics.

Four college-age youth helpers were hired from local northern California colleges and universities, and trained on how to recruit participants ethically, e.g., no coercion of potential participants and recruited on their campuses, dorms, clubs, and through their social networks using flyers and/or postcards with information about the study and the link for the online questionnaire. The youth helpers posted flyers and left postcards in common public spaces, such as libraries, laundromats, coffee shops, and community bulletin boards.

Snowballing technique was also used for recruitment. Upon completion of the questionnaire, participants were provided with a link to share with their similar aged family members and friends who might also be interested in the topic. Participants had the option to enter a drawing for a \$25 Visa e-gift card (one of five drawings) upon study completion.

\section{Measures}

Socio-demographic Characteristics. The predictor variables used as demographics of participants were age; gender; race and ethnicity; educational level; and San Francisco residency. Gender options were male, female, transgender, and other.

Educational level options included high school attendance or completing GED; high school graduate or GED; non-high school graduate; trade, technical, or vocational school; some college, no degree; Associates degree; and Bachelor's degree.

Race and ethnicity options were AfricanAmerican, American Indian/Alaska native, White, Chinese, Filipino (a), Latino (a), Biracial/multiracial, and other. San-Francisco residency was determined via zip codes provided as a write-in option by the participants. Relationship status options included not in a relationship, in a relationship (e.g., with one or more partners), living with a partner, married, or other category.

Mental Health. The question for knowing a family member or friend with depression read, "Do you know anyone, family member or close friend, who has ever met with a mental health professional to get help for a mental health concern like depression?" The question for lifetime mental health services utilization read, "Have you ever met with a mental health professional to get help for a mental health concern like depression?" The options were no or yes; there were four options with the "yes" response: social worker, counselor/therapist, psychologist, or psychiatrist. The question for previous mental health services utilization read, "Have you ever met with a mental health professional to get help for a mental health concern like depression in the last year?" The options were "no" or "yes"; there were four options with the "yes" response: social worker, counselor/therapist, psychologist, or psychiatrist. Current mental health status (depression) was measured using the Patient Health Questionnaire (PHQ-2) which is a brief, multipurpose instrument for the screening of depression (Kroenke, Spitzer, \& Williams, 2003). The PHQ2 has been used in previous research involving community samples, including youth populations (Klein, Ciotoli, \& Chung, 2011; Lakkis \& Mahmassani, 2015; Richardson et al., 2010). A score of 3 points or greater screens positive for depression.

There were two questions on alcohol and marijuana use. These questions were used with permission from the American College Health Association (American College Health 
Zorrilla, M., Modeste, N., Gleason, P., Sealy, D., Banta, J., Trieu, S./ Californian Journal of Health Promotion 2019, Volume 17, Issue 1, Pages 71-83.

Association (ACHA), 2015). Six options ranged from "never used" to "daily use."

Mental Health Literacy. The MHL section of the questionnaire opened with an introduction, "Would you know when your friend or family member is going through a hard time? Please read the description and respond what you think" (An, Jin, \& Brown, 2009, p. 265). Then, the following vignette on depression with suicidal ideation modified from Jorm, Wright, and Morgan (2007) was used:

Daniel is a 21-year-old who has been feeling unusually sad and miserable for the last few weeks. He is tired all the time and has trouble sleeping at night. Daniel doesn't feel like eating and has lost weight. He can't keep his mind on what he needs to do. He puts off making any decisions and even day-to-day tasks seem too much for him. Family and friends are very concerned about him. Daniel feels that he will never be happy again and believes his family and friends would be better off without him. Daniel has been so desperate, he has been thinking of ways to end his life.

From Reavley et al. (2014), a question ("What, if anything, would you say is the matter with Daniel?") was used to determine the participants' ability to recognize the mental health problem. Possible labels for participants to select included: anxiety/anxious; depression; depression with suicidal thoughts; physical problem; stress; other (with fill in option); and don't know (Reavley \& Jorm, 2011; Wright, Jorm, \& Mackinnon, 2012). A score of one point was assigned for the correct label of depression with suicidal thoughts.

Next, a series of questions regarding the beliefs about the helpfulness and harmfulness of types of health care providers and other interventions for mental disorders were given (Reavley et al., 2014). The first question asked, "If Daniel were to seek help from any of the following people, is it likely to be helpful, harmful, or neither for him?" Some examples of health care providers include a family/general practice medical doctor, a pharmacist, or a social worker. The second question asked, "If Daniel were to take one of the following medicines, is it likely to be helpful, harmful or neither for him?" Some examples of medicines included analgesics and antidepressants. The final question was "If Daniel were to undertake any of the following, is it likely to be helpful, harmful, or neither for him?" Some examples of the activities included becoming more physically active, hypnosis, and receiving information about his problem from a health educator.

The MHL score was determined from the responses and assigned one point each if participants selected HELPFUL for the following interventions: (a) a typical family GP or doctor, (b) a psychiatrist, (c) a psychologist, (d) becoming more physically active, (e) reading about people with similar problems and how they have dealt with them, (f) psychotherapy, (g) cognitive behavioural therapy, (h) cutting out alcohol altogether, and (i) antidepressants. Dealing with the problem alone (which is HARMFUL) was also assigned one point. The MHL score for depression with suicidal thoughts ranged from 0 (low level of MHL) to 11 (high level of MHL).

\section{Data Collection}

The translation of surveys from English to Spanish and Chinese was done using Qualtrics (Qualtrics, 2016); surveys were reviewed by native language speakers before being posted. Qualtrics was also used collect survey responses. The survey was accessible via smartphone or computer and completed at the location of the participants' choosing. It took approximately 12 minutes to complete.

All participants were given a unique participant identification. Upon survey completion, contact information was obtained from participants who wanted to enter a raffle drawing for a \$25 Visa egift card. Those who elected for the raffle drawing were required to enter their name and email address in Qualtrics for randomization in the choosing of the winner after the data gathering. An independent database of identifying information was created automatically through a function in Qualtrics. This function ensured that participant identifiers were separate from corresponding survey responses. 
Zorrilla, M., Modeste, N., Gleason, P., Sealy, D., Banta, J., Trieu, S./ Californian Journal of Health Promotion 2019, Volume 17, Issue 1, Pages 71-83.

\section{Analyses}

Statistical Package for the Social Sciences (SPSS) (Version 24.0), was used to import the responses of the Qualtrics online survey for data analysis. Pearson's product-moment correlation coefficient were run to determine the correlation between the background predictors and MHL. Percentage frequencies and 95\% confidence intervals were used to assess participants' beliefs of helpful interventions for depression; participants who correctly labeled the depression vignette were compared to those who incorrectly labeled the depression vignette.

\section{Results}

Table 1 displays the demographic characteristics of the participants. Study participants were mostly white (35.3\%), Latino (25\%), and Chinese (21\%), with the remainder (35\%) representing smaller racial and/or ethnic groups. Additionally, they were predominantly English speaking (87.2\%) and female (58.6\%), with nearly half of the sample attending college $(49.5 \%)$. Over half of the participants were 21 to 24 years old (59.1\%) and San Francisco residents (67.7\%). Almost half of the sample (49.8\%) were in a relationship (e.g., living with a partner, married, or in a relationship with one or more partners). Based on the PHQ-2, about one-third of the participants (31.6\%) screened positive for depression. The percentage of lifetime professional help-seeking with a mental health professional was nearly half of the sample $(49.5 \%, n=213)$ and of those, 31.6\% $(n=136)$ had met with a mental health professional (MHP) in the last year. Two-thirds knew of a family member or friend with depression (66.7\%). Regarding substance usage, 59.3\% reported alcohol use and 32.3\% reported marijuana use in the past 30 days.
Table 1.

Descriptive Statistics of the Sample $(n=430)$

\begin{tabular}{|c|c|}
\hline Characteristics & $n(\%)$ \\
\hline \multicolumn{2}{|l|}{ Gender } \\
\hline Female & $252(58.6)$ \\
\hline Male & 169 (39.3) \\
\hline Transgender & $4(0.9)$ \\
\hline Other & $5(1.2)$ \\
\hline \multicolumn{2}{|l|}{ Age, years } \\
\hline $18-20$ & $176(40.9)$ \\
\hline $21-24$ & $254(59.1)$ \\
\hline \multicolumn{2}{|l|}{ Highest educational level } \\
\hline Attending HS/GED & $13(3.0)$ \\
\hline HS graduate/GED & $61(14.2)$ \\
\hline Not HS graduate & $3(0.7)$ \\
\hline Trade/tech/vocational school & $1(0.2)$ \\
\hline Attending college, no degree & $213(49.5)$ \\
\hline Associates degree & $35(8.1)$ \\
\hline Bachelor's degree & $104(24.2)$ \\
\hline San Francisco resident & $291(67.7)$ \\
\hline \multicolumn{2}{|l|}{ Race and/or Ethnicity ${ }^{\mathrm{a}}$} \\
\hline White & $152(35.3)$ \\
\hline Latino(a) & 109 (25.3) \\
\hline Chinese & $93(21.6)$ \\
\hline Bi-racial/multi-racial & $46(10.7)$ \\
\hline Other & $43(10.0)$ \\
\hline Filipino(a) & $39(9.1)$ \\
\hline African American & $19(4.4)$ \\
\hline American Indian/Alaska Native & $5(1.2)$ \\
\hline \multicolumn{2}{|l|}{ Primary language(s) spoken at home ${ }^{a}$} \\
\hline English & $375(87.2)$ \\
\hline Spanish & $78(18.1)$ \\
\hline Cantonese & $52(12.1)$ \\
\hline Tagalog & $15(3.5)$ \\
\hline Mandarin & $13(3.0)$ \\
\hline Other & $25(5.8)$ \\
\hline \multicolumn{2}{|l|}{ Relationship Status } \\
\hline In a relationship/married & $214(49.8)$ \\
\hline PHQ-2 & \\
\hline Scored 3 points or greater & $136(31.6)$ \\
\hline $\begin{array}{l}\text { Knows family member/friend w } \\
\text { depression }\end{array}$ & 287 (66.7) \\
\hline $\begin{array}{l}\text { Met with a mental health provider } \\
\text { (lifetime) }\end{array}$ & $213(49.5)$ \\
\hline $\begin{array}{l}\text { Met with a mental health provider } \\
\text { (past year) }\end{array}$ & $136(31.6)$ \\
\hline Substance use & \\
\hline Alcohol use (past 30 days) & 255 (59.3) \\
\hline Marijuana use (past 30 days) & 139 (32.3) \\
\hline
\end{tabular}


The correlation between MHL for depression with suicidal thoughts (as measured by the MHL scale) and background factors was investigated using Pearson product-moment correlation coefficient. As outlined in Table 2, several background factors were positively, though weakly, correlated to MHL based on the $\mathrm{r}$ coefficient. They were: being female $[r=.12$, $\mathrm{p}<.05]$, being white $[\mathrm{r}=.12, \mathrm{p}<.05]$, San Francisco residency $[\mathrm{r}=.09, \mathrm{p}<.1]$, and being in $\mathrm{a}$ relationship $[\mathrm{r}=.08, \mathrm{p}<.1]$. Being male $[\mathrm{r}=-.13$, $\mathrm{p}<.05$ ] was negatively, though weakly, correlated to MHL.

Table 2.

Correlations Background Factors and Mental Health Literacy

\begin{tabular}{lr}
\hline Variable & $\mathrm{r}$ \\
\hline PHQ-2 & -.03 \\
Met with MHP (life time) & -.006 \\
Met with MHP (last year) & -.004 \\
White & $.10^{*}$ \\
Chinese & -.08 \\
Latino & -.004 \\
Alcohol & .008 \\
Marijuana & -.012 \\
High School & -.05 \\
College Degree & .02 \\
San Francisco resident & .09 \\
Relationship & .09 \\
Minor (under 21) & -.013 \\
Female & $.12^{*}$ \\
Male & $-.13^{*}$ \\
Knows family/friend with & \\
depression & .07 \\
\hline
\end{tabular}

** Bivariate $\mathrm{r} \leq 0.01$, 2-tailed.

* Bivariate $r \leq 0.05$, 2-tailed.

As seen in Table 3, using MHL as an outcome variable in the stepwise linear regression analysis found the predictors being white $[\beta=.12, p<.05]$, female $[\beta=.12, \quad p<.05]$, and San Francisco residency $[\beta=.09, \quad \mathrm{p}<.1]$ to be statistically significant. Based on the standardized Beta, being white contributed the most to the model, followed by being female, and being a San Francisco resident. The model accounts for 3\% of the variance in MHL.

Table 3.

Predictors of Mental Health Literacy

\begin{tabular}{lrrr}
\hline Variable & $\mathrm{B}$ & $\beta$ & $95 \% \mathrm{CI}$ \\
\hline Constant & $5.41^{* * *}$ & & $4.73,6.09$ \\
Female & $0.76^{* *}$ & 0.12 & $0.14,1.38$ \\
White race & $0.81^{* *}$ & 0.12 & $0.17,1.45$ \\
San & & & \\
Francisco & $0.64^{*}$ & 0.09 & $-0.02,1.30$ \\
$\mathrm{R} \wedge 2$ & 0.034 & & \\
adj $\mathrm{R} \wedge 2$ & 0.027 & & \\
$\mathrm{~F}$ & 5.022 & & \\
${ }^{*} \mathrm{p}<.10,{ }^{* *} \mathrm{p}<.05,{ }^{* * *} \mathrm{p}<.01$ & &
\end{tabular}

The survey question "What, if anything, would you say is the matter with Daniel?" was used to determine the participants' ability to recognize the mental health problem. Percentage frequencies and 95\% confidence intervals were used to assess participants' who correctly labeled "depression with suicidal thought" for the vignette and to assess the beliefs of helpful interventions for depression. The percentage [95\% confidence interval (CI)] of those who correctly labeled "depression with suicidal thought” for the vignette was $87.4 \%$ (CI: $84.3 \%$, 90.6\%).

Table 4 displays the $95 \%$ confidence interval (CI) for those who correctly labeled the vignette and their beliefs regarding the likely helpfulness of interventions. When comparing participants who correctly labeled the vignette to those who did not label correctly, the following people were seen as helpful: counselors/therapists 89.9\% [86.8, 92.9] vs $72.2 \%[60.1,84.3]$ and health educators $77.3 \%$ [73.1, 81.6] vs. 59.3\% [46.1, 72.5]. These results were significantly different. For medications, the following were seen as helpful: sedatives/hypnotics $2.9 \%$ [1.2, 4.6] vs $14.8 \%$ $[5.2,24.4]$ and tranquilizers $4 \%[2.0,6.0]$ vs. 16.7 $\%[6.7,26.7]$. These results were significantly different. For activities, the following were seen as helpful: wellness courses (e.g., relaxation, stress management, meditation, or yoga) $82.7 \%$ 
$[78.9,86.5]$ vs. $64.8 \%$ [51.9, 77.7], cutting out alcohol, $71.8 \%$ [67.3, 76.4] vs. 53.7\% [40.3, 67.1], and an occasional alcoholic drink 6.7\% [4.1, 9.2] vs. 25.9\% [14.1, 37.7].
These results were significantly different. While not statistically significant, a low percentage of participants reported that having "Daniel” handle his problem on his own was helpful, 3.7\% [1.8, $5.6]$ vs. $11.1 \%$ [2.6, 19.6].

Table 4.

Beliefs Regarding the Likely Helpfulness of Intervention

\begin{tabular}{|c|c|c|c|c|}
\hline & \multicolumn{2}{|c|}{$\begin{array}{l}\text { Correct Label } \\
(\mathrm{N}=376)\end{array}$} & \multicolumn{2}{|c|}{$\begin{array}{l}\text { Incorrect Label } \\
\quad(\mathrm{N}=54)\end{array}$} \\
\hline & $\%$ & $95 \% \mathrm{CI}$ & $\%$ & $(95 \% \mathrm{CI})$ \\
\hline Counselor/therapist** & 89.9 & $86.8,92.9$ & 72.2 & $60.1,84.3$ \\
\hline Physical activity & 87 & 83.6, 90.4 & 77.8 & $66.6,89.0$ \\
\hline Relaxation/meditation/yoga** & 82.7 & $78.9,86.5$ & 64.8 & $51.9,77.7$ \\
\hline $\begin{array}{l}\text { Reading about people/same problem } \\
\text { Receiving info about problem from }\end{array}$ & 78.2 & $74.0,82.4$ & 63 & $50.0,76.0$ \\
\hline health educator** & 77.3 & $73.1,81.6$ & 59.3 & $46.1,72.5$ \\
\hline Psychologist & 74.1 & $69.7,78.6$ & 57.4 & $44.1,70.7$ \\
\hline Cutting out alcohol** & 71.8 & $67.3,76.4$ & 53.7 & $40.3,67.1$ \\
\hline Getting out more & 70.2 & $65.6,74.8$ & 57.4 & $44.1,70.7$ \\
\hline Psychiatrist & 65.7 & $60.9,70.5$ & 50 & $36.5,63.5$ \\
\hline Help/close friends & 64.4 & $59.5,69.2$ & 63 & $50.0,76.0$ \\
\hline Help/close family & 60.6 & $55.7,65.6$ & 64.8 & $51.9,77.7$ \\
\hline Telephone hotline & 60.5 & $55.6,65.5$ & 53.7 & $40.3,67.1$ \\
\hline Consulting a book/problem & 58.1 & $53.1,63.1$ & 53.7 & $40.3,67.1$ \\
\hline MD/nurse practitioner & 53.7 & $48.7,58.8$ & 55.6 & $42.2,69.0$ \\
\hline Psychotherapy & 53.3 & $48.3,58.4$ & 50.0 & $36.5,63.5$ \\
\hline Cognitive behavior therapy & 53.1 & $48.0,58.1$ & 50 & $36.5,63.5$ \\
\hline Antidepressants & 50.3 & $45.2,55.3$ & 34 & $21.1,46.9$ \\
\hline Consulting website/problem & 49.9 & $44.8,54.9$ & 50 & $36.5,63.5$ \\
\hline Social worker & 42.4 & $37.4,47.4$ & 51.9 & $38.4,65.4$ \\
\hline Vitamins & 29.5 & $24.9,34.1$ & 42.6 & 29.3, 55.9 \\
\hline Special diet & 28 & $23.4,32.6$ & 25.9 & $14.1,37.7$ \\
\hline Clergy/minister & 20.5 & $16.4,24.6$ & 24.1 & $12.6,35.6$ \\
\hline Naturopath/herbalist & 14.4 & $10.9,18.0$ & 20.8 & $9.8,31.8$ \\
\hline Pharmacist & 13.3 & $9.9,16.8$ & 16.7 & $6.7,26.7$ \\
\hline Hospital/psych ward & 12.8 & $9.4,16.2$ & 20.4 & $9.6,31.2$ \\
\hline Hypnosis & 11.7 & $8.5,15.0$ & 20.4 & $9.6,31.2$ \\
\hline Occasional alcoholic drink** & 6.7 & $4.1,9.2$ & 25.9 & $14.1,37.7$ \\
\hline Electroconvulsive therapy & 6.1 & $3.7,8.6$ & 18.5 & $8.0,29.0]$ \\
\hline
\end{tabular}


Zorrilla, M., Modeste, N., Gleason, P., Sealy, D., Banta, J., Trieu, S./ Californian Journal of Health Promotion 2019, Volume 17, Issue 1, Pages 71-83.

\begin{tabular}{|c|c|c|c|c|}
\hline \multicolumn{5}{|c|}{$\begin{array}{c}\text { Table } 4 . \\
\begin{array}{c}\text { Beliefs Regarding the Likely Helpfulness of } \\
\text { Intervention (cont'd) }\end{array}\end{array}$} \\
\hline & \multicolumn{2}{|c|}{$\begin{array}{c}\text { Correct Label } \\
(\mathrm{N}=376)\end{array}$} & \multicolumn{2}{|c|}{$\begin{array}{c}\text { Incorrect Label } \\
(\mathrm{N}=54)\end{array}$} \\
\hline & $\%$ & $95 \% \mathrm{CI}$ & $\%$ & $95 \% \mathrm{CI}$ \\
\hline Antibiotics & 5.3 & $3.0,7.6$ & 11.1 & 2.6, 19.6 \\
\hline Analgesics & 4.8 & $2.6,6.9$ & 11.1 & 2.6, 19.6 \\
\hline $\begin{array}{l}\text { Anti- } \\
\text { psychotics } \\
\text { Tranquilizers } \\
\text { (such as }\end{array}$ & 4.8 & $2.6,6.9$ & 13 & $4.0,22.0$ \\
\hline $\begin{array}{l}\text { valium)** } \\
\text { Deal on his }\end{array}$ & 4 & $2.0,6.0$ & 16.7 & 6.7, 26.7 \\
\hline $\begin{array}{l}\text { Deal on his } \\
\text { own } \\
\text { Sedatives/ }\end{array}$ & 3.7 & $1.8,5.6$ & 11.1 & 2.6, 19.6 \\
\hline hypnotics** & 2.9 & $1.2,4.6$ & 14.8 & $5.2,24.4$ \\
\hline
\end{tabular}

\section{Discussion}

The findings from this study suggest that several predictor variables (being white, female, and a San Francisco resident) predicted MHL among a diverse group of young adults. Correlations between MHL and predictor variables (age; gender; race and ethnicity; educational level; San Francisco residency; depression status; knowing a family member or friend with depression; alcohol use; marijuana use; lifetime and previous mental health services utilization) were examined, followed by linear regression to identify which variables predicted MHL. Additionally, a high percentage of participants recognized the description of depression with suicidal ideation used in the vignette with a variety of responses regarding beliefs of helpful interventions for a person with depression.

Previous studies on MHL have some comparable results to the present study. For example, in an Australian study of adolescents and young adults (ages 15 to 25, $\mathrm{n}=502$ ) by Reavley and Jorm (2011) found participants who were given a depression with suicidal thought vignette labeled it as depression (83.6\%). In a general population study of teens and adults (aged 15 and older, $\mathrm{n}=1,008$ ) in Australia, Reavley et al. (2014) found that women had higher MHL levels than men $(\mathrm{r}=.38, \mathrm{p}<.01)$. In a study of college students (ages 18 to 24, $n=774$ ) in Australia, being female was associated with correctly labeling depression in the vignette (Reavley et al., 2012). In a recent MHL study of adults $(n=2,622)$ in the United States (Miller et al., 2017), 77\% of women recognized depression.

In the current study, being a San Francisco resident predicted MHL. Findings showed that a very high percentage of participants (87.4\%) recognized and correctly labeled the depression with suicidal ideation vignette. Participants in the study may have been exposed to anti-stigma campaigns and/or received behavioral health services in high school or college in San Francisco. For example, San Francisco has 19 wellness centers and one school-based health center that provide behavioral health services in all public high schools (Ambresin, Bennett, Patton, Sanci, \& Sawyer, 2013). It may be possible that some survey participants, nearly $68 \%$ of whom were San Francisco residents, may have learned about depression and suicide and/or received behavioral health services through their health centers. Correctly identifying the vignette is important as it tends to activate people into seeking help for mental health treatment (Jorm, 2012; Miller et al., 2017).

There were interesting findings regarding the helpfulness of interventions for the person described in the vignette. When asked about the helpfulness of several types of people, participants rated counselors/therapists the highest percentage (89.9\% who correctly labeled the vignette, $72.2 \%$ who incorrectly labeled the vignette), followed by health educators (77.3\%, $59.3 \%)$, and psychologists (74.1\%, 57.4\%). Additionally, participants rated medical providers such as general practice (53.7\% and $55.6 \%$ ) and psychiatrists (65.7\% and 50\%) on a lower percentage level. This was different from the previously cited research by Reavley and Jorm (2011) who found that participants rated close friends at the highest percentage (93.5\%, CI: 90.6-95.6), closely followed by counselors (93.4\%, CI: 90.5-95.5), and general practice (GP) or family doctor (89.8\%, CI: 86.7-92.3). A possible reason for the difference may be due to the older age range (18 -24 years old) of the participants in the current study. 
Zorrilla, M., Modeste, N., Gleason, P., Sealy, D., Banta, J., Trieu, S./ Californian Journal of Health Promotion 2019, Volume 17, Issue 1, Pages 71-83.

When asked about the helpfulness of medications, participants who correctly labeled the vignette rated antidepressants the highest percentage $(50.3 \%)$, followed by vitamins (29.5\%), and antibiotics (5.3\%). In contrast, participants who incorrectly labeled the vignette rated vitamins the highest percentage $(42.6 \%)$, followed by antidepressants (34\%), and tranquilizers (16.7\%, CI: 6.7, 26.7). Prior research findings by Reavley and Jorm (2011) found participants rated antidepressants the highest (61.5\%, CI: 56.8, 66.0), followed by vitamins (48.4\%, CI: 43.7, 53.2), and antipsychotics (22.2\%, CI: 18.5, 26.5).

In terms of helpfulness of self-help interventions, engaging in physical activities (87\%, CI; 83.6, 90.4 ) and relaxation training/meditation/yoga (82.7\%, CI: 78.9, 86.5) were rated fairly high. Other studies, however, found participants who rated these interventions even higher. In the previously cited study by Reavley and Jorm (2011), participants rated physical activity very high (90.7\%, CI: 87.4, 93.2), followed by relaxation training (90.3\%, CI: 87.2, 92.7), and meditation (80.7\%, CI: 76.7, 84.1). In another study by Reavley et al. (2012) conducted among 18-24-year-old college students $(n=774)$, both physical activity and relaxation training were highly rated by the participants (94\%, CI: 93, 95).

Beliefs regarding the helpfulness of alcohol was mixed. While reducing alcohol was seen as helpful $\mathbf{( 7 1 . 8 \%}$ who correctly labeled the vignette, $53.7 \%$ who incorrectly labeled the vignette), having an occasional alcoholic drink was also seen as helpful $(6.7 \%, 25.9 \%)$. These results were in sharp contrast to previously cited MHL studies by Reavley and Jorm (2011): 88.1\% of the participants believed reducing alcohol and $2.7 \%$ of the participants believed having an occasional drink were helpful interventions. Similarly, Reavley et al. (2012) found $89 \%$ of the participants believed reducing alcohol and $2 \%$ of the participants believed using alcohol to relax were helpful. In the current study, almost a third (31.6\%) of the participants screened positive for depression and over half (59.3\%) used alcohol in the last 30 days. Depression, suicide ideation, and alcohol use are especially serious problems that occur among college students (Pedrelli,
Nyer, Yeung, Zulauf, \& Wilens, 2015). Although alcohol can be legally consumed at age 21, it may be used by young adults who are depressed to self-medicate and as a coping mechanism (Marmorstein, Iacono, \& Malone, 2010).

\section{Limitations}

Some limitations of this study include its crosssectional design; therefore, we cannot determine causality. Moreover, the non-randomized sampling and geographical setting may limit generalizability. Self-selection bias may also be a factor due to convenience sampling. Participants might have been more motivated to take an online survey or might have been interested in the topic. Also, insufficient numbers of non-students participated in the study, thus the findings may not apply to that population.

\section{Conclusions}

Most of the young adults in this study could recognize depression with suicidal ideation with low percentages of selecting the appropriate interventions to help the person in the vignette. Given the findings, there is a need for improving mental health literacy among young adults especially for males and Latino and Chinese populations. Young adults need to be made more aware of mental health treatment options that are available for depression (Goldney et al., 2002), ranging from professional help-seeking interventions from a psychiatrist or counselor to self-care strategies. With respect to self-care strategies, young adults would benefit from learning about strategies they can use to help with depression such as engaging in physical activity, among others (SAMHSA, 2017b). Health educators and mental health professionals in college-based student health centers can be instrumental in dissemination of health education information on depression and developing programs that support self-care strategies e.g., walking club, yoga classes, or support groups. Finally, this mental health literacy study assessed participants' beliefs about the helpfulness of alcohol use only. Given the prominent role of alcohol on college campuses, health educators and mental health professionals may need to consider integrating alcohol prevention education when designing mental health literacy 
Zorrilla, M., Modeste, N., Gleason, P., Sealy, D., Banta, J., Trieu, S./ Californian Journal of Health Promotion 2019, Volume 17, Issue 1, Pages 71-83.

interventions. Future mental health literacy studies should also assess beliefs about the helpfulness of other drugs such as marijuana, given the legalization of marijuana for recreational use in states such as California (Fuller, 2018).

\section{References}

Ambresin, A.-E., Bennett, K., Patton, G. C., Sanci, L. A., \& Sawyer, S. M. (2013). Assessment of youthfriendly health care: a systematic review of indicators drawn from young people's perspectives. Journal of Adolescent Health, 52(6), 670-681. doi:http://doi.org/10.1016/j.jadohealth.2012.12.014

American College Health Association (ACHA). (2015). American College Health Association - National College Health Assessment (ACHA-NCHA-II) Reference Group Date Report - Spring 2015 Undergraduates. Retrieved from http://www.acha-ncha.org/docs/NCHAII\%20WEB SPRING 2015 REFERENCE GROUP DATA REPORT.pdf

An, S., Jin, H. S., \& Brown, J. D. (2009). Direct-to-Consumer antidepressant ads and young adults' beliefs about depression. Health Marketing Quarterly, 26(4), 259-278. doi:10.1080/07359680903303981

Berkman, N. D., Davis, T. C., \& McCormack, L. (2010). Health literacy: what is it? Journal of Health Communication, 15 Suppl 2, 9-19. doi:10.1080/10810730.2010.499985

CDC. (2015). What is health literacy? Retrieved from http://www.cdc.gov/healthliteracy/learn/index.html

CDC. (2018). 10 leading caues of death by age group, United States - 2016. Retrieved from https://www.cdc.gov/injury/wisqars/pdf/leading_causes_of_death_by_age_group_2016-508.pdf

Centers for Disease Control and Prevention (CDC). (2011). Mental health surveillance among adults in the United States. MMWR. Retrieved from http://www.cdc.gov/mmwr/pdf/other/su6003.pdf

Chamberlain, P. N., Goldney, R. D., Taylor, A. W., \& Eckert, K. A. (2012). Have mental health education programs influenced the mental health literacy of those with major depression and suicidal ideation? A comparison between 1998 and 2008 in South Australia. Suicide and Life-Threatening Behavior, 42(5), 525-540. doi:10.1111/j.1943-278X.2012.00109.x

Cheng, H.-L., Wang, C., McDermott, R. C., Kridel, M., \& Rislin, J. L. (2018). Self-stigma, mental health literacy, and attitudes toward seeking psychological help. Journal of Counseling \& Development, 96(1), 64-74. doi:10.1002/jcad.12178

Coles, M. E., \& Coleman, S. L. (2010). Barriers to treatment seeking for anxiety disorders: initial data on the role of mental health literacy. Depress Anxiety, 27(1), 63-71. doi:10.1002/da.20620

Coles, M. E., Ravid, A., Gibb, B., George-Denn, D., Bronstein, L. R., \& McLeod, S. (2016). Adolescent mental health literacy: Young people's knowledge of depression and social anxiety disorder. Journal of Adolescent Health, 58(1), 57-62. doi:10.1016/j.jadohealth.2015.09.017

Faul, F., Erdfelder, E., Lang, A.-G., \& Buchner, A. (2007). G*Power: A flexible statistical power analysis program for the social, behavioral, and biomedical sciences. Behavior Research Methods, 39, $175-191$.

Fuller, T. (2018). Recreational pot is officially legal in California. New York Times. Retrieved from https://www.nytimes.com/2018/01/01/us/legal-pot-california.html

Goldney, R. D., Fisher, L. J., Wilson, D. H., \& Cheok, F. (2002). Mental health literacy of those with major depression and suicidal ideation: An impediment to help seeking. Suicide and LifeThreatening Behavior, 32(4), 394-403. doi:10.1521/suli.32.4.394.22343

Jorm, A. F. (2000). Mental health literacy: Public knowledge and beliefs about mental disorders. British Journal of Psychiatry, 177, 396 - 401.

Jorm, A. F. (2012). Mental health literacy: Empowering the community to take action for better mental health. American Psychologist, 67(3), 231-243. doi:10.1037/a0025957

Jorm, A. F. (2015). Why We Need the Concept of "Mental Health Literacy". Health Communication, 30(12), 1166-1168. doi:10.1080/10410236.2015.1037423 
Zorrilla, M., Modeste, N., Gleason, P., Sealy, D., Banta, J., Trieu, S./ Californian Journal of Health Promotion 2019, Volume 17, Issue 1, Pages 71-83.

Jorm, A. F., Korten, A. E., Jacomb, P. A., Christensen, H., Rodgers, B., \& Politt, P. (1997). "Mental health literacy": A survey of the public's ability to recognize mental disorders and their beliefs about the effectiveness of treatment. The Medical Journal of Australia, 166, 182-186.

Jorm, A. F., Wright, A., \& Morgan, A. J. (2007). Where to seek help for a mental disorder? National survey of the beliefs of Australian youth and their parents. The Medical Journal of Australia, 187, 556-560.

Kelly, C. M., Jorm, A. F., \& Wright, A. (2007). Improving mental health literacy as a strategy to facilitate early intervention. The Medical Journal of Australia, 187, S26-S30.

Klein, M. C., Ciotoli, C., \& Chung, H. (2011). Primary care screening of depression and treatment engagement in a university health center: A retrospective analysis. Journal of American College Health, 59, 289-295.

Kroenke, K., Spitzer, R., \& Williams, J. B. W. (2003). The Patient Health Questionnaire - 2: validity of a two-item depression screener. Medical Care, 41, 128401292.

Lakkis, N. A., \& Mahmassani, D. M. (2015). Screening instruments for depression in primary care: A concise review for clinicians. Postgraduate Medicine, 127, 99-106.

Lam, L. T. (2014). Mental health literacy and mental health status in adolescents: A population-based survey. Child and Adolescent Psychiatry and Mental Health, 8(1), 26.

Manganello, J. A., Sentell, T., \& Davis, T. C. (2013). Health literacy, mental health, and adolescents. In W. T. O'Donohue, L. T. Benuto, \& L. W. Tolle (Eds.), Handbook of Adolescent Health Psychology (pp. 143-151). New York, NY: Springer.

Marmorstein, N. R., Iacono, W. G., \& Malone, S. M. (2010). Longitudinal associations between depression and substance dependence from adolescence through early adulthood. Drug and Alcohol Dependence, 107(2-3), 154-160. doi:http://dx.doi.org/10.1016/j.drugalcdep.2009.10.002

Miller, P. K., Cuthbertson, C., Skidmore, M., \& Loveridge, S. (2017). Depression. Retrieved from http://msutoday.msu.edu//pdf/assets/2017/depression-pdf.pdf

Patton, G. C., Coffey, C., Romaniuk, H., Mackinnon, A., Carlin, J. B., Degenhardt, L., . . . Moran, P. (2014). The prognosis of common mental disorders in adolescents: a 14-year prospective cohort study. The Lancet, 383(9926), 1404-1411. doi:http://dx.doi.org/10.1016/S0140-6736(13)62116-9

Pedrelli, P., Nyer, M., Yeung, A., Zulauf, C., \& Wilens, T. (2015). College Students: mental health problems and treatment considerations. Academic Psychiatry, 39, 503-511. doi:10.1007/s40596014-0205-9

Qualtrics. (2016). Retrieved from http://www.qualtrics.com

Reavley, N. J., \& Jorm, A. F. (2011). Young people's recognition of mental disorders and beliefs about treatment and outcome: Findings from an Australian national survey. Australian and New Zealand Journal of Psychiatry, 45, 890-898. doi:10.3109/00048674.2011.614215

Reavley, N. J., McCann, T. V., \& Jorm, A. F. (2012). Mental health literacy in higher education students. Early Intervention in Psychiatry, 6(1), 45-52. doi:10.1111/j.1751-7893.2011.00314.x

Reavley, N. J., Morgan, A. J., \& Jorm, A. F. (2014). Development of scales to assess mental health literacy relating to recognition of and interventions for depression, anxiety disorders and schizophrenia/psychosis. Australian and New Zealand Journal of Psychiatry, 48(1), 61-69. doi:10.1177/0004867413491157

Richardson, L. P., Rockhill, C., Russo, J. E., Grossman, D. C., Richards, J., McCarty, C., . . Katon, W. (2010). Evaluation of the PHQ-2 as a brief screen for detecting major depression among adolescents. Pediatrics, 125(5), e1097-1103. doi:10.1542/peds.2009-2712

Rickwood, D., Deane, F. P., Wilson, C. J., \& Ciarrochi, J. (2005). Young people's help-seeking for mental health problems. Australian e-Journal for the Advancement of Mental Health, 4(3), 218-251. doi:10.5172/jamh.4.3.218

SAMHSA. (2017a). Key substance use and mental health indicators in the United States: Results from the 2016 National Survey on Drug Use and Health. Retrieved from https://www.samhsa.gov/data/sites/default/files/NSDUH-FFR1-2016/NSDUH-FFR1-2016.htm

SAMHSA. (2017b). Understanding depression - young adults: Get the facts. 
Zorrilla, M., Modeste, N., Gleason, P., Sealy, D., Banta, J., Trieu, S./ Californian Journal of Health Promotion 2019, Volume 17, Issue 1, Pages 71-83.

Substance Abuse and Mental Health Services Administration (SAMHSA). (2017). Key substance use and mental health indicators in the United States: Results from the 2016 National Survey on Drug Use and Health. Retrieved from https://www.samhsa.gov/data/sites/default/files/NSDUH-FFR12016/NSDUH-FFR1-2016.htm

Thai, Q., \& Nguyen, T. (2018). Mental health literacy: knowledge of depression among undergraduate students in Hanoi, Vietnam. International Journal of Mental Health Systems. doi:10.1186/s13033-018-0195-1

Thapar, A., Collishaw, S., Pine, D. S., \& Thapar, A. K. (2012). Depression in adolescence. The Lancet, 379(9820), 1056-1067. doi:http://dx.doi.org/10.1016/S0140-6736(11)60871-4

Wilens, T. E., \& Rosenbaum, J. F. (2013). Transitional aged youth: A new frontier in child and adolescent psychiatry. Journal of the American Academy of Child \& Adolescent Psychiatry, 52(9), 887-890. doi:http://dx.doi.org/10.1016/j.jaac.2013.04.020

Wright, A., Jorm, A. F., \& Mackinnon, A. (2012). Labels used by young people to describe mental disorders: Which ones predict effective help-seeking choices? Social Psychiatry \& Psychiatric Epidemiology, 47(6), 917-926. doi:10.1007/s00127-011-0399-z

Author Information

Márcia Mónica Zorrilla

Loma Linda University

School of Public Health

C: 415-859-1163

Email: drmarciamzorrilla@gmail.com

* corresponding author 